\title{
Study On The Structures And Interactions Binary System Composed By The Ionic Liquids [Bmim][Ala] and Water /Methanol Using The Vibrational Spectra
}

\author{
Siqi Yan, Hua Zhang, Jianhua Liu and Haijun Wang \\ School of Chemical and Material Engineering, Jiangnan University, Wuxi 214122, China
}

\begin{abstract}
The molecular geometry and vibrational frequencies of the Amino acid ILs 1-butyl-3-methylimidazolium a-aminopropionic acid salt ([bmim][Ala]), [bmim][Ala] and water /Methanol were investigated by the density functional theory (DFT) at the hybrid Becke 3-Lee-Yang-Parr (B3LYP)/6-311++G* level. Attenuated total reflectionFourier transform infrared spectroscopy (ATR-FTIR) of the [bmim][Ala], [bmim][Ala] and water /Methanol have been recorded at different concentrations. The observed vibrational spectra have been resolved and assigned in detail by comparison to the calculated results. The results indicate that the vibrational frequencies obtained by DFT (B3LYP) are in good agreement with the experiment results. The forms and the effect of the hydrogen bond that exist between [bmim][Ala] and water/Methanol have been investigated from the point view of the interaction.
\end{abstract}

Keywords: 1-butyl-3-methylimidazolium a-aminopropionic acid salt; Density functional theory; Water; Methanol; Vibrational Spectra

\section{Introduction}

In 2005, Hiroyuki Ohno and his coworkers developed a series of novel amino acid ionic liquids (AAILs) coupling the imidazolium cation with 20 different natural amino acids $[1,2]$. So that the AAILs become one of the most rapidly growing new research areas of ionic liquids (ILs) [3-5]. Its known that ionic liquids have some unique physical and chemical properties which including the negligibly small vapor pressure, high thermal stability, high ionic conductivity, and wide range of solubility [6-10]. As a kind of "green" solvent,the ILs have the potential to replace the traditional industrial molecular solvents [11-13].

Except that the unique physical and chemical properties that mentioned above, AAILs also possess the great merit of low costs, biodegradable, and a variety of sources from nature [14,15]. Further functional design for AAILs is also expected carboxyl group or various functional groups on the side chain of the amino acids. Extensive experimental studies have been performed on ILs and AAILs [1618]. However, it is far from enough to summarize a general rule that can predict the physicochemical properties of the ILs for a specific application [19]. Because the features that control the physicochemical properties of ILs remain poorly understood. Thus, it is essential to understand the intermolecular forces and the IL's structure for the development of special and tunable properties of ILs. A set of theoretical methods have now been used to study ILs. Traditional molecular dynamics simulations, first-principles molecular dynamics simulations and electronic structure methods have been applied to ILs to obtain useful information on ILs [19,20].

The presence of water or Methanol in ionic liquids has a large effect on physical properties. There are a number of papers, which have studied the physical properties of binary systems of ionic liquids $[21,22]$. However, few reports related to the structures and the AAILs mixtures interactions of AAILs at theoretical level have been found, the mechanism of the cation-anion interaction for AAILs has not been fully understood. It is necessary to investigate these interaction systems systematically by theoretical or experimental methods. Among various experimental techniques, infrared spectroscopy is a convenient and effective approach for the study of $\mathrm{H}$-bonding interactions at the molecular level. In this paper, the structures and interactions of the [bmim][Ala], [bmim][Ala] and water /Methanol have been systematically studied by density functional theory, the ATR-IR spectra of the [bmim][Ala], [bmim][Ala] and water /Methanol were investigated. The results will be helpful for understanding of these AAILs from the perspective of structure and the AAILs mixtures interactions, and it could provide some important information for the continuous exploitation and application of AAILs.

\section{Experimental Section}

\section{Sample preparation}

The Amino acid ILs [bmim][Ala] was purchased from Sigma Co.Ltd, which was used after drying under vacuum at $323 \mathrm{~K}$. The samples were analyzed by Karl Fisher titration and showed a mass\% of water lower than $1 \times 10^{-4}$ for [bmim] [Ala]. Samples of [bmim][Ala]Water /[bmim][Ala]-Methanol solutions for ATR-IR, measurements were prepared by weighing dried ionic liquid and doubly distilled water ,Methanol (AR, mass fraction $>0.99)$

\section{The ATR-IR spectroscopy}

ATR-IR measurements with a single reflectance on [bmim] [Ala] $-\mathrm{H}_{2} \mathrm{O}$ solutions at $x_{\mathrm{w}}=0.29,0.45,0.56,0.63$, and 0.68 were made at a room temperature by using a PerkinElmer Spectrum 100 FT-IR spectrometer equipped with an attenuated total reflectance

*Corresponding author: Haijun Wang, School of Chemical and Materia Engineering, Jiangnan University, Wuxi 214122, China, Tel: 009702255844; Email: wanghj329@hotmail.com

Received April 25, 2015; Accepted May 20, 2015; Published May 25, 2015

Citation: Yan S, Zhang H, Liu J, Wang H (2015) Study On The Structures And Interactions Binary System Composed By The lonic Liquids [Bmim][Ala] and Water / Methanol Using The Vibrational Spectra. J Biomol Res Ther 4: 125. doi:10.4172/21677956.1000125

Copyright: (c) 2015 Yan S, et al. This is an open-access article distributed under the terms of the Creative Commons Attribution License, which permits unrestricted use, distribution, and reproduction in any medium, provided the original author and source are credited. 
Citation: Yan S, Zhang H, Liu J, Wang H (2015) Study On The Structures And Interactions Binary System Composed By The lonic Liquids [Bmim] [Ala] and Water /Methanol Using The Vibrational Spectra. J Biomol Res Ther 4: 125. doi:10.4172/2167-7956.1000125

Page 2 of 9

(ATR) cell with 16 scans at $2 \mathrm{~cm}^{-1}$ resolution. The mole fractions of Methanol in [bmim][Ala]-Methanol mixtures are 0.16, 0.28,0.36, 0.42 , and 0.49 .

\section{Calculations}

DFT [23-25] calculations were carried out using Gaussian 03 [26] program package. Natural bond orbital $(\mathrm{NBO})[27,28]$ analysis and atoms in molecules (AIM) [29] analysis were both used to analyze the nature of the [bmim][Ala], [bmim][Ala] and water /Methanol interactions at the B3LYP/6-311++ $\mathrm{G}^{* \star}$ level [30-32]. All calculations were performed using Gaussian 03 program, except that AIM calculation was performed by AIM 2000 package [33] and used the B3LYP/6-311++G $\mathrm{G}^{* *}$ results as input. To confirm that full geometry optimizations and normal frequency analyses were carried out at each optimized geometry. The normal mode animations were visualized using the Gauss-view program. Normal coordinate analysis was performed to obtain a detailed assignment of the normal vibrational modes.

\section{Results and Discussion}

\section{Geometrical structure}

A series of stable ion pairs had been optimized. These ion pairs are used to detect the interaction between the ion pairs and the water molecule, the ion pairs and the Methanol molecule.

The [bmim][Ala]-Methanol binary system was optimized, and six stable configurations obtained with no imaginary frequencies are presented in Figure1 The selected geometrical parameters of these configurations are showed in Figure 1.

Most of the early investigations suggested that the miscibility of an ionic liquid with water is mostly determined by the associated anion. The [bmim][Ala] $-\mathrm{H}_{2} \mathrm{O}$ binary system was optimized, and seven stable configurations obtained with no imaginary frequencies are presented in Figure 2. The selected geometrical parameters of these configurations are showed in Figure 2.

The intermolecular and intramolecular $\mathrm{H}$ bonds were both characterized by the bond length and bond angle in Figure 1 and Figure 2, where a $\mathrm{H}$ bond will be indicated if the $\mathrm{C}-\mathrm{H} \ldots \mathrm{O}$ distance is less than the van der Waals $\mathrm{H}$... O distance of $2.72 \AA$ and the $\mathrm{C}-\mathrm{H}$... O angle is greater than $90^{\circ}[34]$.

Further comparison in configurations a1-a6 found that there are three main types of structures. Methanol molecule only has interaction with the anion of ionic liquid, as a6. Methanol molecule only has interaction with the cation of ionic liquid, as a4. Methanol molecule has interaction with the cation-anion of ionic liquid, as a1, a2, a3, a5. Similarly, [bmim][Ala]- $\mathrm{H}_{2} \mathrm{O}$ also has three main types of structures, Water molecule only has interaction with the anion of ionic liquid, like b2,b7. Water molecule only has interaction with the cation of ionic liquid, as b4, b6. Water molecule has interaction with the cation-anion of ionic liquid, as b1, b3, b5.

Generally, the total energy will decrease when two molecules interact. The decreased energy is called interaction energy, or binding energy. The stability of complex is related to interaction energy tightly. The basis set superposition error (BSSE) is calculated with the counterpoise procedure method advanced by Boys and Bernardi [35]. Table 1 shows the interaction energies for [bmim]
[Ala]-Methanol/[bmim][Ala]- $\mathrm{H}_{2} \mathrm{O}$ complexes, $\Delta E_{\text {AAIL }}$, including the BSSE energy [36], $\Delta E c p$, and the interaction energy corrected by BSSE $\Delta E_{\mathrm{M}}$.

a The interaction energies of the ion pairs, ${ }^{\mathrm{b}}$ The interaction energies of the ion pairs corrected by BSSE $\Delta E_{\mathrm{M}}=\Delta E \mathrm{cp}-\Delta E_{\mathrm{AAIL}}$

Configuration $\mathbf{a} \mathbf{1}$ and $\mathbf{a} 3, \mathbf{b} \mathbf{1}$ and $\mathbf{b 5}$ with the interaction energy of -450.52 and $-452.14 \mathrm{~kJ} / \mathrm{mol},-451.27$ and $-452.19 \mathrm{~kJ} / \mathrm{mol}$ (BSSE corrected) were predicted to be the more stable configurations. The intensity orders of the interactions for the configurations are $\mathbf{a} 3=\mathbf{a} 1>$ $\mathrm{a} 2=\mathrm{a} 5=\mathrm{a} 6>\mathrm{a} 4, \mathrm{~b} 5=\mathrm{b} 1=\mathrm{b} 3>\mathrm{b} 2=\mathrm{b} 7>\mathrm{b} 4=\mathrm{b} 6$.

Table 1 lists the interaction energies of these complexes. Compared with the interaction energies of the anion-cation, water complexes, the interaction energies of these ion pair-water complexes are smaller. The interaction energies of the complexes a1, a3, b1, b5 are 53.62, 56.79, 54.35 and $57.77 \mathrm{~kJ} / \mathrm{mol}$ (Table 1), respectively. Addition of water or Methanol have a strong impact on the structure and interaction of cation-anion of [bmim][Ala]. The smaller the interaction energies are, the lower the effect on the structure.

Natural bond orbital analysis. The electronic population was studied by NBO analysis, which transforms the canonical delocalized Hartree-Fock molecular orbital into, localized orbital that are closely tied to chemical bonding concepts. Table 2 shows the delocalization energies corresponding to the most important orbital interactions together with the occupancy of the acceptor orbital and the orbital energy differences.

$\mathrm{BD}^{*}$, antibonding orbital; LP, lone pair; $\mathrm{RY}^{\star}$ empty atomic orbital out of valance orbital

It can be seen that there are some main orbital interactions $\mathrm{LP}(\mathrm{O}) \rightarrow \mathrm{BD}^{*}(\mathrm{O}-\mathrm{H}), \mathrm{LP}(\mathrm{O}) \rightarrow \mathrm{BD}^{*}(\mathrm{C}-\mathrm{H})$ in these complexes. The $\mathrm{NBO}$ analysis has revealed that the $\mathrm{LP}(\mathrm{O}) \rightarrow \mathrm{BD}^{*}(\mathrm{C}-\mathrm{H})$ interactions give the strongest stabilization to these complexes and strengthen the intermolecular $\mathrm{H}$... O interactions.

AIM analysis: The bond properties between each pair of atoms were systemically analyzed using atoms in molecules (AIM) theory. To gain a deeper insight into the nature of interactions, AIM calculations were undertaken at the B3LYP/6-311++ $\mathrm{G}^{* *}$ level of theory. It is used to analyze the bonding characteristic, which is based on a topological analysis of electron density $\left(\rho_{c}\right)$ and Laplacian $\left(\nabla^{2} \rho_{c}\right)$ [37]. $\rho_{c}$ is used to describe the strength of a bond, with stronger bond associated with larger $\rho_{c}$ value. $\nabla^{2} \rho_{c}$ describes the characteristic of the bond. As $\nabla^{2} \rho_{c}<0$, it is named as the covalent bond. As $\nabla 2 \rho c>0$, it refers to a closed-shell interaction and characteristic of ionic bond, hydrogen bond or van der Waals interaction. As $\nabla 2 \rho c \approx 0$, it forms faintish chemical bond.

From the values listed in Table 3 , it can be concluded that the interactions between the cation and the anion, AAIL and Methanol/ Water, which were marked by the dot line were all close shell systems ( $\mathrm{H}$ bonding interaction), for their values of the $\nabla^{2} \rho_{c}$ all fall in the range of normal H-bond (0.020 0.139 au), and $\rho$ c is no more than 0.20 au. While for the H38-O39 in a, O38-H39 in $\mathbf{b}$ etc were all $\nabla^{2} \rho_{c}<0$, and the corresponding $\rho \mathrm{c}$ were all is greater than $0.20 \mathrm{au}$, they were characterized by covalent bonds.

On the basis of the AIM topological analysis, the $\mathrm{H} \cdot \mathrm{O}$ and $\mathrm{H} \cdots \mathrm{N}$ interactions occupy bigger proportion for the complex, The $\mathrm{H}$ bonds were formed between the [bmim][Ala] and Methanol molecule, [bmim][Ala] and Water molecule. 

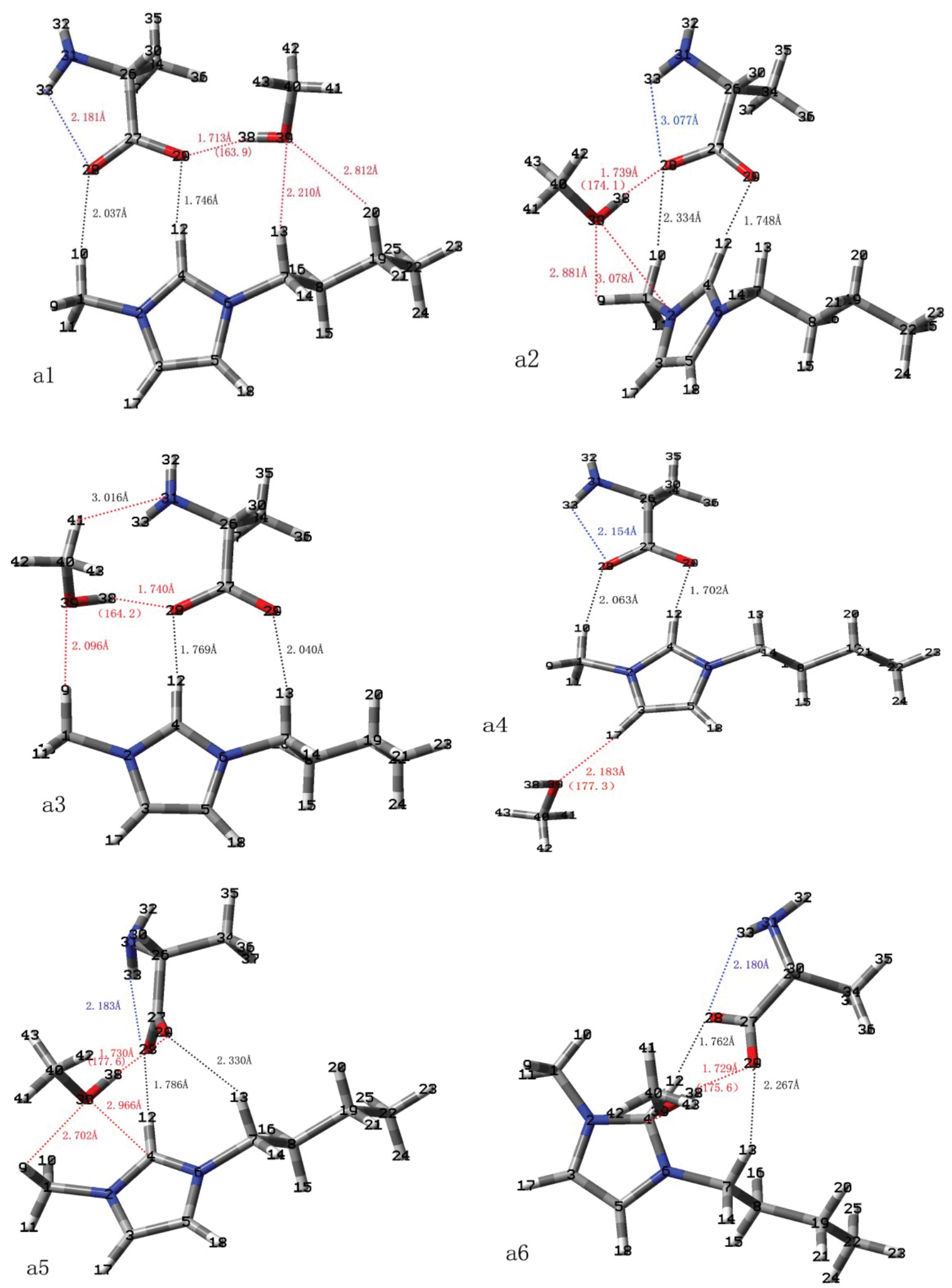

Figure 1: Optimized structures of [bmim][Ala]-Methanol (B3LYP/6-311++G**): a1, a2, a3, a4,a5,a6. Hydrogen bonds are indicated by dotted lines and the corresponding lengths ( $(\AA)$ and angles (deg) (in parentheses) are given. 


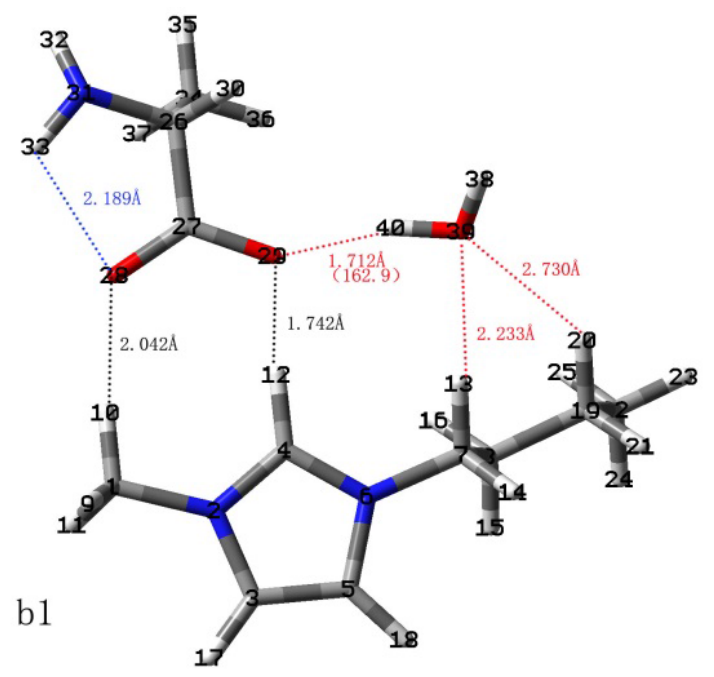

b3
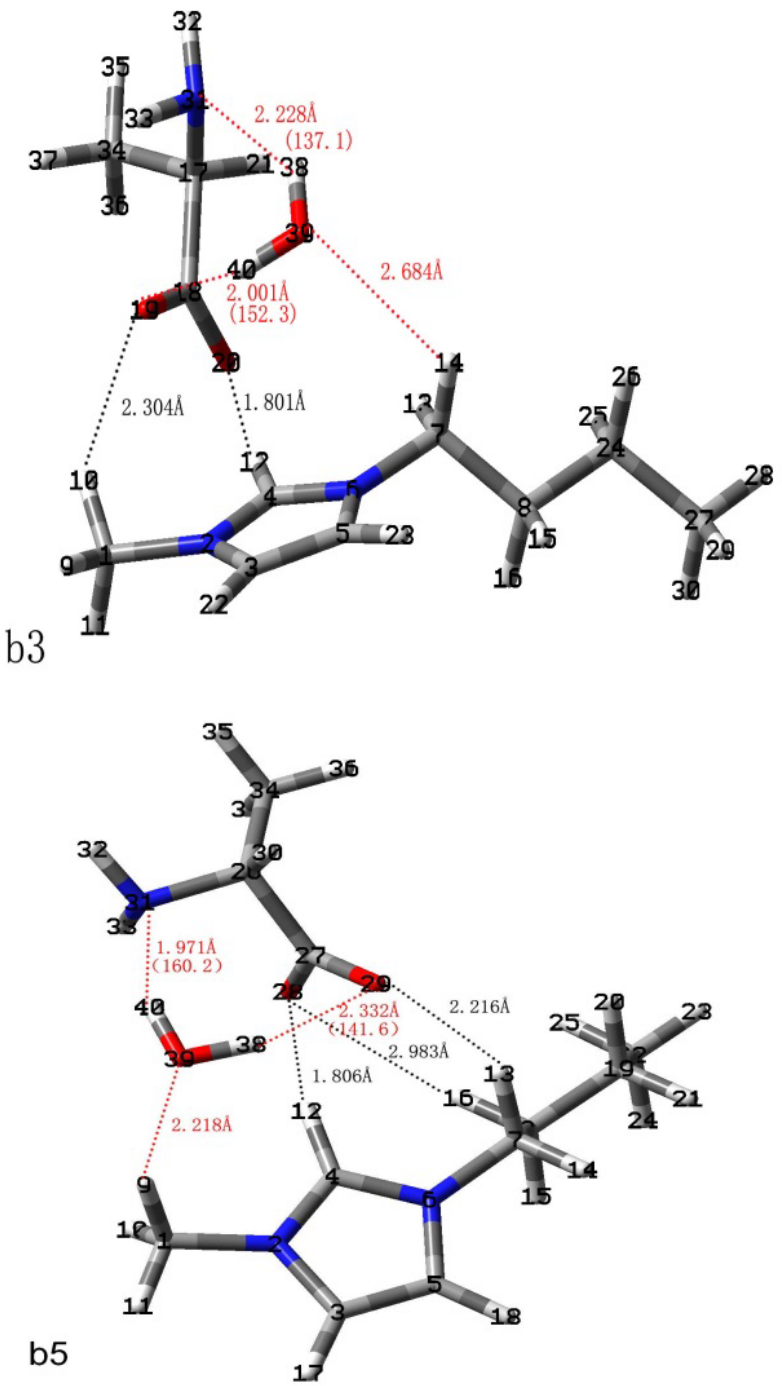
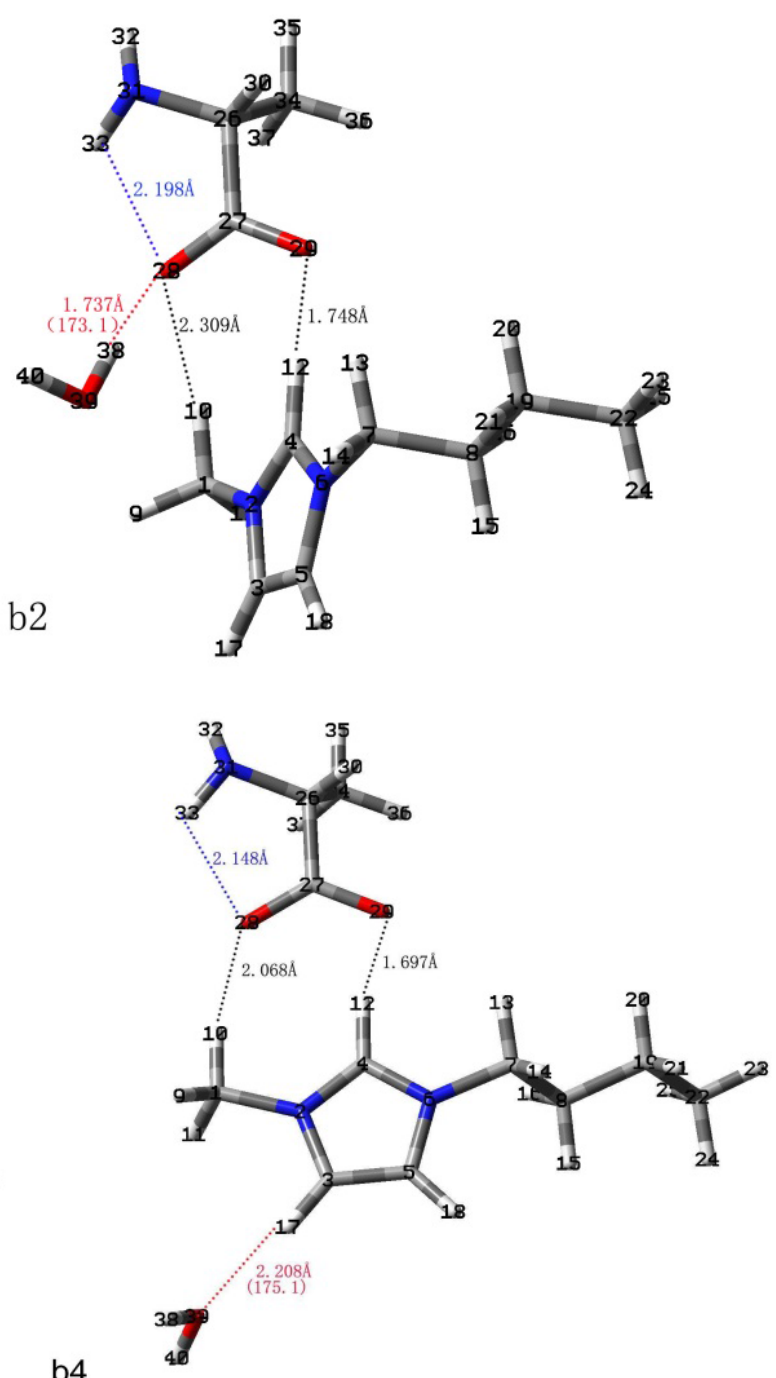

b4

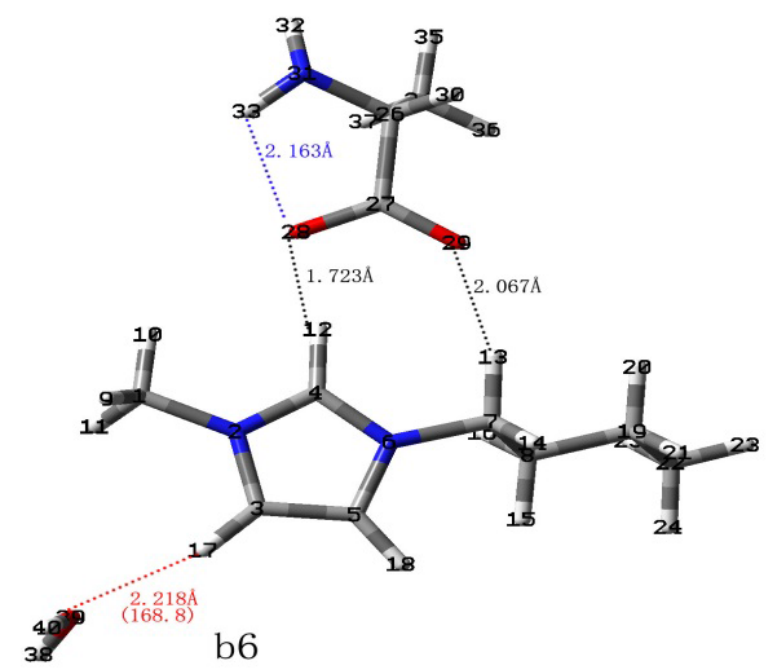


Citation: Yan S, Zhang H, Liu J, Wang H (2015) Study On The Structures And Interactions Binary System Composed By The lonic Liquids [Bmim] [Ala] and Water /Methanol Using The Vibrational Spectra. J Biomol Res Ther 4: 125. doi:10.4172/2167-7956.1000125

Page 5 of 9

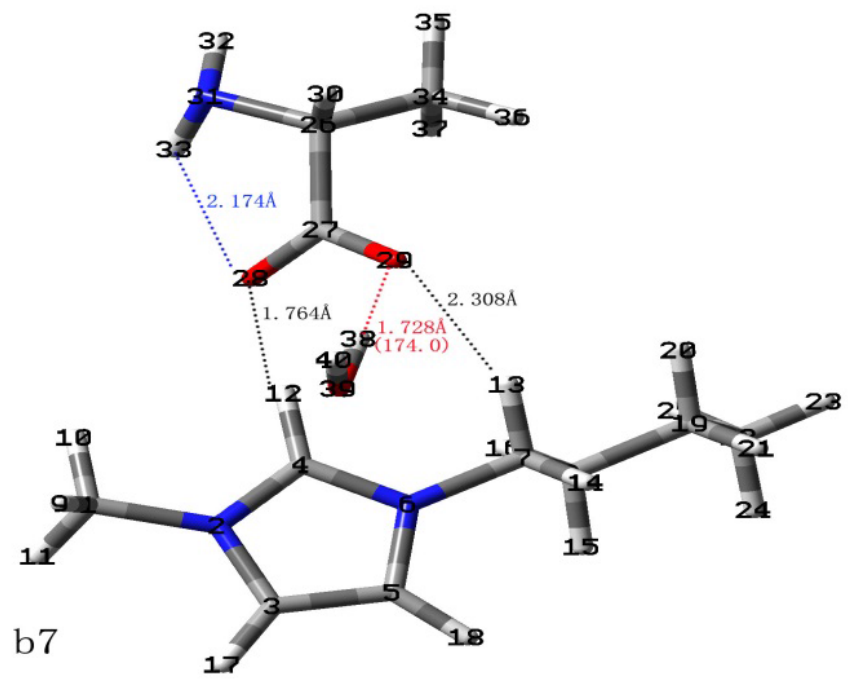

Figure 2: Optimized structures of [bmim][Ala]-H2O (B3LYP/6-311++G**): b1, b2, b3, b4,b5,b6,b7. Hydrogen bonds are indicated by dotted lines and the corresponding lengths $(\AA)$ and angles (deg) (in parentheses) are given.

\begin{tabular}{|c|c|c|c|c|c|c|c|}
\hline \multicolumn{8}{|c|}{$\begin{array}{l}\text { B3LYP/6-311++G* } \\
\text { B3LYP/6-311++G }\end{array}$} \\
\hline Complex & $\Delta E \mathrm{cp}$ & $\Delta E_{\mathrm{AAIL}}^{\mathrm{a}}$ & $\Delta E_{\mathrm{M}}^{\mathrm{b}}$ & Complex & $\Delta E \mathrm{cp}$ & $\Delta E_{\mathrm{AAIL}}$ & $\Delta E_{\mathrm{M}}$ \\
\hline a1 & -450.52 & -396.90 & -53.62 & b1 & -451.27 & -396.92 & -54.35 \\
\hline a2 & -441.74 & -392.42 & -49.31 & $\mathrm{~b} 2$ & -443.03 & -392.57 & -50.45 \\
\hline a3 & -452.14 & -395.35 & -56.79 & b3 & -447.05 & -396.18 & -50.87 \\
\hline a4 & -412.99 & -398.93 & -14.07 & b4 & -411.33 & -398.99 & -12.34 \\
\hline a5 & -440.82 & -385.99 & -54.83 & b5 & -452.19 & -394.42 & -57.77 \\
\hline \multirow[t]{2}{*}{ a6 } & -438.73 & -388.84 & -49.88 & b6 & -409.43 & -396.14 & -13.29 \\
\hline & & & & b7 & -439.79 & -388.19 & -51.60 \\
\hline
\end{tabular}

Table 1: Interaction energies of complexes $\Delta E_{\mathrm{CP}}\left(\right.$ all values in $\left.\mathrm{kJ} \mathrm{mol}^{-1}\right)$.

\begin{tabular}{|c|c|c|c|c|c|c|c|}
\hline Complex & Donor & Acceptor & $\mathrm{E}(2) \mathrm{kJ} / \mathrm{mol}$ & Complex & Donor & Acceptor & $\mathrm{E}(2) \mathrm{kJ} / \mathrm{mol}$ \\
\hline \multirow[t]{4}{*}{ a1 } & LP (1) O29 & $\mathrm{BD}^{*}(1) \mathrm{O} 38-\mathrm{H} 39$ & 58.42 & b1 & $\mathrm{LP}(1) \mathrm{O} 29$ & $\mathrm{BD}^{*}(1) \mathrm{O} 39-\mathrm{H} 40$ & 52.98 \\
\hline & LP (2) O29 & $\mathrm{BD}^{*}(1) \mathrm{O} 38-\mathrm{H} 39$ & 14.76 & & LP(2) O29 & $\mathrm{BD}^{*}(1) \mathrm{O} 39-\mathrm{H} 40$ & 14.55 \\
\hline & LP (2) O39 & $\mathrm{BD}^{*}(1) \mathrm{C} 7-\mathrm{H} 13$ & 9.95 & & LP(2) O39 & $\mathrm{BD}^{*}(1) \mathrm{C} 7-\mathrm{H} 13$ & 14.68 \\
\hline & LP (1) O39 & $\mathrm{BD}^{*}(1) \mathrm{C} 7-\mathrm{H} 13$ & 6.77 & $\mathrm{~b} 2$ & $\mathrm{LP}(1) \mathrm{O} 28$ & $\mathrm{BD}^{*}(1) \mathrm{O} 39-\mathrm{H} 38$ & 24.38 \\
\hline \multirow[t]{3}{*}{ a2 } & LP (2) O28 & $\mathrm{BD}^{*}(1) \mathrm{O} 38-\mathrm{H} 39$ & 30.65 & & $\mathrm{LP}(2) \mathrm{O} 28$ & $\mathrm{BD}^{*}(1) \mathrm{O} 39-\mathrm{H} 38$ & 30.11 \\
\hline & LP (3) O28 & $\mathrm{BD}^{*}(1) \mathrm{O} 38-\mathrm{H} 39$ & 29.90 & & $\mathrm{LP}(3) \mathrm{O} 28$ & $\mathrm{BD}^{*}(1) \mathrm{O} 39-\mathrm{H} 38$ & 29.27 \\
\hline & LP (1) O28 & $\mathrm{BD}^{*}(1) \mathrm{O} 38-\mathrm{H} 39$ & 28.06 & b3 & $\mathrm{LP}(1) \mathrm{O} 28$ & $\mathrm{BD}^{*}(1) \mathrm{O} 39-\mathrm{H} 40$ & 4.10 \\
\hline \multirow[t]{4}{*}{ a3 } & LP (1) O39 & $\mathrm{BD}^{*}(1) \mathrm{C} 1-\mathrm{H} 9$ & 11.42 & & $\mathrm{LP}(3) \mathrm{O} 28$ & $\mathrm{BD}^{*}(1) \mathrm{O} 39-\mathrm{H} 40$ & 22.08 \\
\hline & LP (3) O28 & $\mathrm{BD}^{*}(1) \mathrm{O} 38-\mathrm{H} 39$ & 26.01 & & $\mathrm{LP}(1) \mathrm{N} 31$ & $\mathrm{BD}^{*}(1) \mathrm{O} 39-\mathrm{H} 38$ & 16.27 \\
\hline & LP (1) O28 & $\mathrm{BD}^{*}(1) \mathrm{O} 38-\mathrm{H} 39$ & 42.99 & b4 & LP(2) O39 & $\mathrm{BD}^{*}(1) \mathrm{C} 3-\mathrm{H} 17$ & 17.02 \\
\hline & LP (2) O39 & $\mathrm{BD}^{*}(1) \mathrm{C} 1-\mathrm{H} 9$ & 15.26 & b5 & LP(2) O39 & $\mathrm{BD}^{*}(1) \mathrm{C} 1-\mathrm{H} 9$ & 16.43 \\
\hline a4 & LP (1) O39 & $\mathrm{BD}^{*}(1) \mathrm{C} 3-\mathrm{H} 22$ & 17.65 & & LP(1) N31 & $\mathrm{BD}^{*}(1) \mathrm{O} 39-\mathrm{H} 38$ & 49.55 \\
\hline \multirow[t]{3}{*}{ a5 } & LP (3) O29 & $\mathrm{BD}^{*}(1) \mathrm{O} 38-\mathrm{H} 39$ & 35.59 & b6 & LP(2) O39 & $\mathrm{BD}^{*}(1) \mathrm{C} 3-\mathrm{H} 17$ & 16.73 \\
\hline & LP (1) O29 & $\mathrm{BD}^{*}(1) \mathrm{O} 38-\mathrm{H} 39$ & 27.10 & b7 & $\mathrm{LP}(1) \mathrm{O} 29$ & $\mathrm{BD}^{*}(1) \mathrm{O} 39-\mathrm{H} 38$ & $\begin{array}{c}23.9 \\
2\end{array}$ \\
\hline & LP (2) O29 & $\mathrm{BD}^{*}(1) \mathrm{O} 38-\mathrm{H} 39$ & 30.82 & & $\mathrm{LP}(2) \mathrm{O} 29$ & $\mathrm{BD}^{*}(1) \mathrm{O} 39-\mathrm{H} 38$ & 33.45 \\
\hline \multirow[t]{3}{*}{ a6 } & LP (1) O29 & $\mathrm{BD}^{*}(1) \mathrm{O} 38-\mathrm{H} 39$ & 26.89 & & LP(3) O28 & BD*(1)O39 - H38 & 31.32 \\
\hline & LP (2) O29 & $\mathrm{BD}^{*}(1) \mathrm{O} 38-\mathrm{H} 39$ & 35.75 & & & & \\
\hline & LP (3) O29 & $\mathrm{BD}^{*}(1) \mathrm{O} 38-\mathrm{H} 39$ & 31.20 & & & & \\
\hline
\end{tabular}

Table 2: NBO interacting and the corresponding stable energies (kJ.mol-1). 
Citation: Yan S, Zhang H, Liu J, Wang H (2015) Study On The Structures And Interactions Binary System Composed By The lonic Liquids [Bmim] [Ala] and Water /Methanol Using The Vibrational Spectra. J Biomol Res Ther 4: 125. doi:10.4172/2167-7956.1000125

Page 6 of 9

\begin{tabular}{|c|c|c|c|c|c|c|c|}
\hline Complex & Bond & $\rho_{c}$ & $\nabla^{2} \rho_{c}$ & Complex & Bond & $\rho_{c}$ & $\nabla^{2} \rho_{c}$ \\
\hline \multirow[t]{5}{*}{ a1 } & O28- H10 & 0.02227 & 0.07613 & b2 & $\mathrm{O} 28-\mathrm{H} 10$ & 0.013429 & 0.04140 \\
\hline & $\mathrm{O} 29-\mathrm{H} 12$ & 0.04376 & 0.12552 & & $\mathrm{O} 29-\mathrm{H} 12$ & 0.043954 & 0.12421 \\
\hline & $\mathrm{O} 29-\mathrm{H} 38$ & 0.04089 & 0.14173 & & $\mathrm{O} 28-\mathrm{H} 38$ & 0.039499 & 0.12972 \\
\hline & O39-H13 & 0.01561 & 0.05109 & & O28-H33 & 0.019211 & 0.08319 \\
\hline & O39-H25 & 0.00514 & 0.01650 & b3 & $\mathrm{O} 28-\mathrm{H} 10$ & 0.014167 & 0.04352 \\
\hline \multirow[t]{3}{*}{ a2 } & $\mathrm{O} 28-\mathrm{H} 38$ & 0.03953 & 0.13009 & & O29-H12 & 0.038447 & 0.11815 \\
\hline & O39-N2 & 0.00731 & 0.02675 & & $\mathrm{O} 28-\mathrm{H} 40$ & 0.022751 & 0.07821 \\
\hline & О39-H9 & 0.00599 & 0.02544 & & N32- H38 & 0.015332 & 0.05681 \\
\hline \multirow[t]{4}{*}{ a3 } & O28-H38 & 0.03876 & 0.13422 & & O28-H33 & 0.018268 & 0.05254 \\
\hline & O39-H19 & 0.00237 & 0.01834 & & O39-H14 & 0.00745 & 0.02364 \\
\hline & N31-H41 & 0.00463 & 0.01264 & b4 & $\mathrm{O} 28-\mathrm{H} 10$ & 0.020813 & 0.07168 \\
\hline & $\mathrm{O} 28-\mathrm{H} 13$ & 0.02049 & 0.06466 & & $\mathrm{O} 29-\mathrm{H} 12$ & 0.050141 & 0.13026 \\
\hline \multirow[t]{3}{*}{ a4 } & $\mathrm{O} 39-\mathrm{H} 22$ & 0.01499 & 0.05489 & & O39-H17 & 0.013877 & 0.05157 \\
\hline & $\mathrm{O} 28-\mathrm{H} 10$ & 0.02104 & 0.07264 & & $\mathrm{O} 28-\mathrm{H} 33$ & 0.02085 & 0.0852 \\
\hline & O29-H12 & 0.04943 & 0.12960 & b5 & $\mathrm{O} 28-\mathrm{H} 12$ & 0.037614 & 0.11600 \\
\hline \multirow[t]{3}{*}{ a5 } & $\mathrm{O} 28-\mathrm{H} 12$ & 0.04001 & 0.11848 & & O28-H16 & 0.004108 & 0.01348 \\
\hline & $\mathrm{O} 29-\mathrm{H} 13$ & 0.01313 & 0.03927 & & $\mathrm{~N} 31-\mathrm{H} 40$ & 0.030014 & 0.08115 \\
\hline & $\mathrm{O} 29-\mathrm{H} 38$ & 0.04056 & 0.13045 & & $\mathrm{O} 29-\mathrm{H} 38$ & 0.012099 & 0.03807 \\
\hline \multirow[t]{4}{*}{ a6 } & $\mathrm{O} 28-\mathrm{H} 12$ & 0.04234 & 0.12261 & & О39-H9 & 0.016474 & 0.05140 \\
\hline & $\mathrm{O} 29-\mathrm{H} 13$ & 0.01465 & 0.04493 & & O29-H13 & 0.016796 & 0.05283 \\
\hline & $\mathrm{O} 29-\mathrm{H} 38$ & 0.04077 & 0.13174 & b6 & $\mathrm{O} 28-\mathrm{H} 12$ & 0.04682 & 0.12726 \\
\hline & O39-C1 & 0.00843 & 0.03184 & & $\mathrm{O} 29-\mathrm{H} 13$ & 0.021097 & 0.07304 \\
\hline \multirow[t]{6}{*}{ b1 } & O28- H10 & 0.0221 & 0.07526 & & O39-H17 & 0.013815 & 0.05061 \\
\hline & $\mathrm{O} 29-\mathrm{H} 12$ & 0.044143 & 0.12632 & & $\mathrm{O} 28-\mathrm{H} 33$ & 0.020236 & 0.08410 \\
\hline & O29- H40 & 0.040704 & 0.14095 & b7 & $\mathrm{O} 28-\mathrm{H} 12$ & 0.042071 & 0.12207 \\
\hline & O39-H13 & 0.014808 & 0.04907 & & $\mathrm{O} 29-\mathrm{H} 13$ & 0.013617 & 0.04092 \\
\hline & $\mathrm{O} 28-\mathrm{H} 33$ & 0.019732 & 0.08464 & & O29-H38 & 0.040566 & 0.13090 \\
\hline & $\mathrm{O} 39-\mathrm{H} 20$ & 0.005911 & 0.01889 & & $\mathrm{O} 28-\mathrm{H} 33$ & 0.019855 & 0.08444 \\
\hline
\end{tabular}

Table 3: Calculated properties at the bond critical point for all complexes (all values in au).

Although the gas-phase calculation may be different from the liquid state, the results obtained here show us some new insights on the interaction details of the ionic liquids/water, ionic liquids/ Methanol systems. These calculations may be valuable to study to binary liquid-liquid phase systems containing amino acid ionic liquid.

\section{Vibrational spectra}

Recently, spectroscopic methods have been developed to study the structures of solutions $[38,39]$. Among the various spectroscopic methods, infrared spectroscopy and Raman spectroscopy play important roles in investigations on the structural properties and interactions of ionic liquids [40-43]. Exploration of hydrogen-bonding systems in which solvation, considered as a series of equilibria, can be quantified offers an interesting opportunity to explore solvent effects in recognition at a molecular level by combining experiments and theoretical calculation.

The Interaction of the ion-pairs with the water molecule: The ATR-IR spectra of the [bmim] [Ala]- $\mathrm{H}_{2} \mathrm{O}$ in the region $1500-1800 \mathrm{~cm}^{-1}$ is displayed in Figure 3. Some major peaks in the theoretical IR spectra of [bmim] [Ala] $-\mathrm{H}_{2} \mathrm{O}$ and $\mathrm{H}_{2} \mathrm{O}$ are displayed in Figure 4. Correspondingly, assignments for the [bmim][Ala] $-\mathrm{H}_{2} \mathrm{O}$ in the $\mathrm{C}-\mathrm{H}, \mathrm{O}-\mathrm{H}$ stretching region are shown in Table 4. scaling factor 0.9890

The IR band corresponding to the bending mode $\left(v_{2}\right)$ of water (either pure or dissolved in solvents) usually absorbs in the region $1595 \pm 1650 \mathrm{~cm}^{-1}$. However, this band alone is seldom used to elucidate the molecular state of water. We find it with ionic liquid in IR vibrating peaks of the carboxyl group mode together research, a very good description of water in ionic liquid micro structure [44,45]. As is depicted in Figure 3. Although the positions for both vibrations observed in the present study differ from the calculated on [bmim] [Ala] $-\mathrm{H}_{2} \mathrm{O}$ solutions, this tendency agrees with each other. Both from the calculated value, and the experimental data, the basic trend in the bending mode $\left(v_{2}\right)$ of water of $[\mathrm{bmim}][\mathrm{Ala}]-\mathrm{H}_{2} \mathrm{O}$ solutions was to move to higher frequencies of the vibrations spectrum. At the same time, studying on the ATR-IR spectrum found: the water content led to the increase of the maximal infrared absorption peak. The $v_{\mathrm{C}=\mathrm{O}}$ mode of [bmim][Ala] of [bmim][Ala] $-\mathrm{H}_{2} \mathrm{O}$ solutions moved to lower frequencies and the water content led to the decrease of the maximal infrared absorption peak. All of this, indicating hydrogen bond that are the glue holding groups of water molecules and AAIL together are so plentiful in [bmim][Ala] that they play a large role in determining its properties.

The Interaction of the ion-pairs with the methanol molecule: The ATR-IR spectra of the [bmim] [Ala] $-\mathrm{CH}_{3} \mathrm{OH}$ in the region 950 $1200 \mathrm{~cm}^{-1}$ and $1500-1650 \mathrm{~cm}^{-1}$ are displayed in Figure 5 and the C-O stretching mode of Methanol in the theoretical IR spectra is displayed in Figure 6 Correspondingly, assignments for the [bmim] [Ala] $-\mathrm{CH}_{3} \mathrm{OH}$ in the $\mathrm{C}-\mathrm{H}, \mathrm{O}-\mathrm{H}, \mathrm{C}-\mathrm{O}$ stretching region are shown in Table 5.

\section{scaling factor 0.9890 .}

The IR band corresponding to the C-O stretching mode of Methanol (either pure or dissolved in solvents) usually absorbs in the region 980 $\pm 1100 \mathrm{~cm}^{-1}$. Using the same method with analysis of [bmim][Ala]/ 

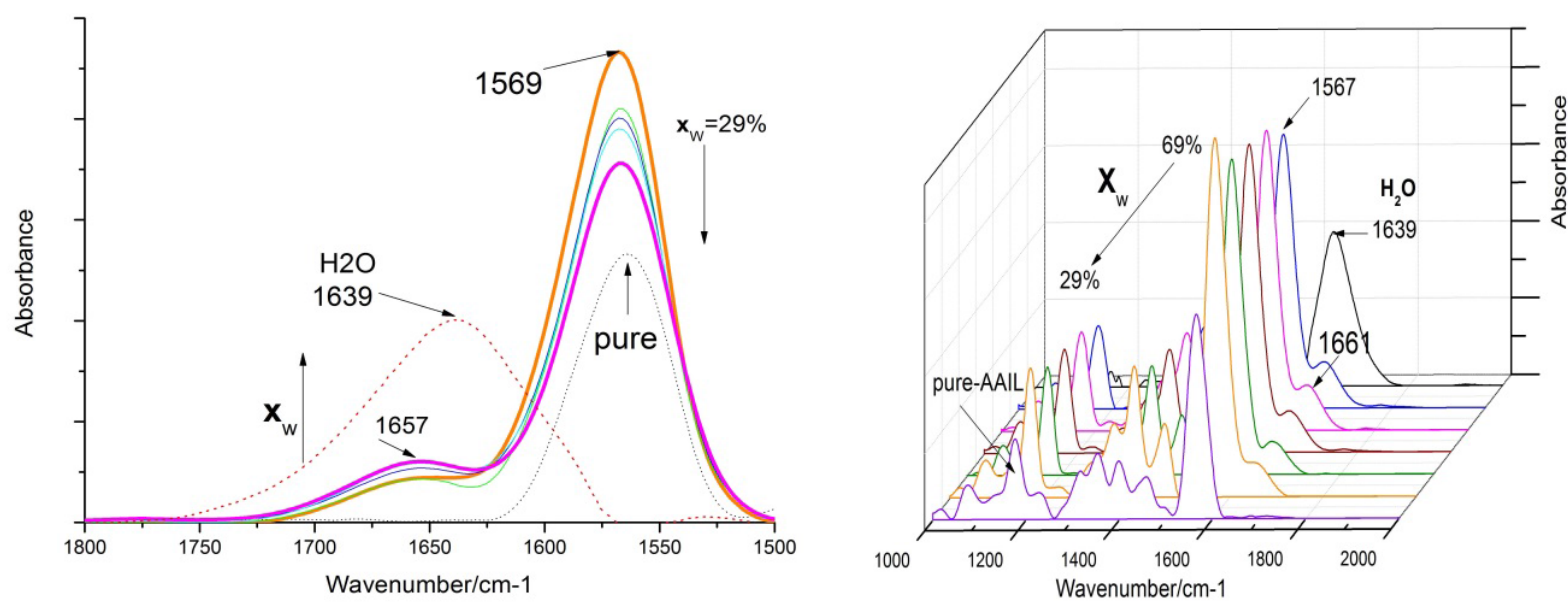

Figure 3: ATR-IR spectra of [bmim][Ala]- $\mathrm{H}_{2} \mathrm{O}$ solutions as a function of water mole fraction. The arrows indicate the change in the mole fraction from $\mathrm{x}_{\mathrm{w}} 0.29$ to 0.69 .

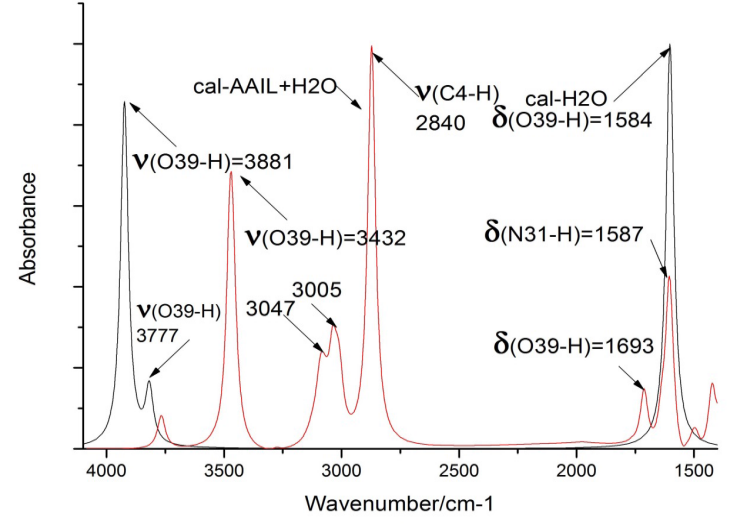

Figure 4: Some major peaks in the theoretical IR spectra of [bmim][Ala]- $\mathrm{H}_{2} \mathrm{O}$ and $\mathrm{H}_{2} \mathrm{O}$.

\begin{tabular}{|c|c|c|c|c|}
\hline \multicolumn{5}{|c|}{$[$ bmim $][$ Ala $]+\mathrm{H}_{2} \mathrm{O}$} \\
\hline & comple & $\delta_{\text {calcd }(03}$ & $\delta_{\text {calcd(N31-H) }}$ & $\mathbf{v}_{\text {obs }}$ \\
\hline b1 & 2692.1 & 1646.7 & 1580.4 & \multirow{4}{*}{ - Dobs $(\mathrm{O} 38-\mathrm{H})=1656$} \\
\hline b2 & 2720.7 & 1645.7 & 1555.7 & \\
\hline b3 & 2834.5 & 1691.2 & 1580.4 & \\
\hline b4 & 2596.1 & 1609.1 & 1547.8 & \\
\hline b5 & 2840.4 & 1693.2 & 1591.3 & \multirow{3}{*}{$\delta$ obs $(\mathrm{N} 31-\mathrm{H})=1569$} \\
\hline b6 & 2661.4 & 1610.1 & 1564.6 & \\
\hline b7 & 2753.4 & 1642.7 & 1552.7 & \\
\hline AAIL & 2739.5 & --- & 1614.0 & 1659 \\
\hline $\mathrm{H}_{2} \mathrm{O}$ & --- & 1584 & --- & 1639 \\
\hline
\end{tabular}

Table 4: Values of some major peaks in the theoretical and experimental IR spectra of [bmim] [Ala] $+\mathrm{H}_{2} \mathrm{O}$.

Water, we known that the positions for both vibrations observed in the present study differ from the calculated on solutions, this tendency agrees with each other. the basic trend in the $\mathrm{C}$-O stretching mode of Methanol of [bmim][Ala] $-\mathrm{CH}_{3} \mathrm{OH}$ solution was to move to higher frequencies of the vibrations spectrum. At the same time, study on the ATR-IR spectrum found: the Methanol content led to the increase of the maximal infrared absorption peak. The $v_{\mathrm{C}=\mathrm{O}}$ mode of [bmim] [Ala] of [bmim][Ala] $-\mathrm{CH}_{3} \mathrm{OH}$ solutions moved to lower frequencies and the Methanol content led to the decrease of the maximal infrared absorption peak.

Furthermore, we have also made clear assignments of certain vibrations of AAILs in the IR region, which is also very useful for further investigations of complex systems of mixed of AAILs solution, which would be different due to the existence of various amounts of water or Methanol. This observation is very helpful for practical applications of AAILs in future. The results of experiments show the correctness of analysis.

\section{Conclusions}

The interactions of some kinds of structure of [bmim][Ala]- $\mathrm{H}_{2} \mathrm{O}$ and [bmim] [Ala] $-\mathrm{CH}_{3} \mathrm{OH}$ were investigated using ATR-IR and DFT methods, On the basis of calculation and experiment results, the main conclusions are summarized as follows:

It was found that the interactions between $[\mathrm{bmim}]^{+}$and [Ala] are mainly characterized by the electrostatic attractions. The intramolecular $\mathrm{H}$ bond system is one of the influence factors of the interactions between the cation and anion. Moreover, hydrogen bonds play a dominant role in the energy level of ionic liquids solution and the configuration characteristics.

The interactions between AAILs and $\mathrm{H}_{2} \mathrm{O}$ or $\mathrm{CH}_{3} \mathrm{OH}$ depended on the hydrogen bonds based on the results of AIM and NBO. Configuration of the high interaction energy is that Water or Methanol has hydrogen bonding with both cation and anion at the same time. The $\mathrm{NBO}$ analysis has revealed that the $\mathrm{LP}(\mathrm{O}) \rightarrow \mathrm{BD}^{*}(\mathrm{C}-\mathrm{H})$ interactions give the strongest stabilization to these complexes and strengthen the intermolecular $\mathrm{H}$... O interactions. In other words, hydrogen bonds have the greatest impact for the carbonyl and hydroxyl groups.

The addition of Water or Methanol to AAILs has a large effect on macroscopic properties, which is consistent with theoretic calculation. The change of vibration frequency of $\mathrm{C} 4-\mathrm{H}$ is in accordance with the previous results that the site acting was the carboxyl group mode. As a preliminary investigation on relationships between the electron density of H-bonding and stretching frequencies by IR and DFT, this work will make a contribution to the study of the microstructure for AAIL mixed solution. 
Citation: Yan S, Zhang H, Liu J, Wang H (2015) Study On The Structures And Interactions Binary System Composed By The lonic Liquids [Bmim] [Ala] and Water /Methanol Using The Vibrational Spectra. J Biomol Res Ther 4: 125. doi:10.4172/2167-7956.1000125
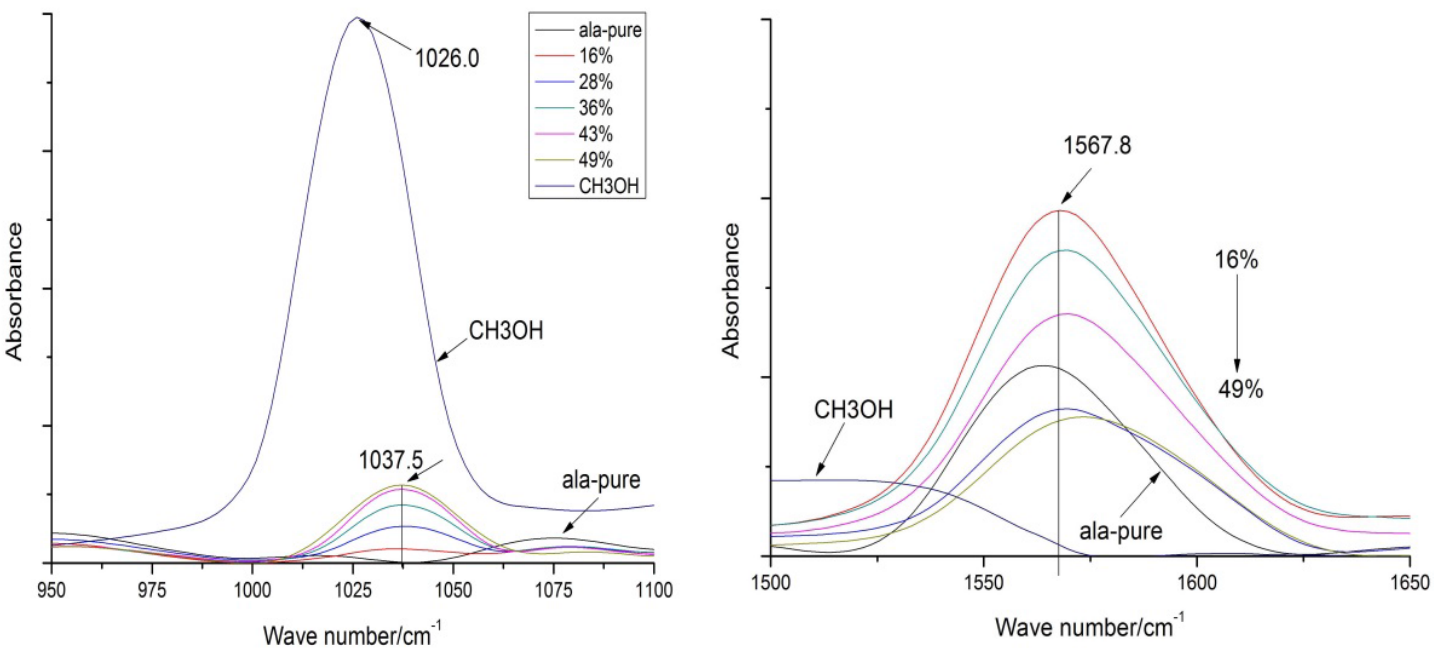

Figure 5: ATR-IR spectra of [bmim][Ala] $-\mathrm{CH} 3 \mathrm{OH}$ solutions as a function of water mole fraction. The arrows indicate the change in the mole fraction from $\times \mathrm{M} 0.16$ to 0.49 .

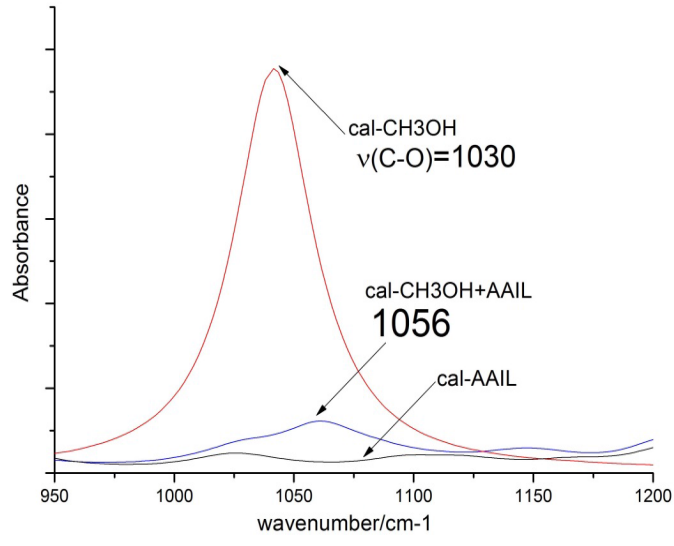

Figure 6: $\mathrm{v}_{\text {calcd }(038-\mathrm{C})}$ peaks in the theoretical IR spectra of [bmim][Ala]- $\mathrm{CH}_{3} \mathrm{OH}$ and $\mathrm{CH}_{3} \mathrm{OH}$.

\begin{tabular}{|c|c|c|c|c|}
\hline \multicolumn{5}{|c|}{$[\mathrm{bmim}][\mathrm{Ala}]+\mathrm{CH}_{3} \mathrm{OH}$} \\
\hline \multicolumn{5}{|c|}{ complex $\mathbf{v}_{\text {calcd(C4-H) }} \mathbf{v}_{\text {calcd(O38-C) }} \mathbf{v}_{\text {calcd( O38-H) }} \mathbf{v}_{\text {obs }}$} \\
\hline a1 & 2696.7 & 1057.0 & 3361.3 & \multirow{4}{*}{ vobs $(\mathrm{O} 38-\mathrm{C})=1037.5$} \\
\hline a2 & 2722.3 & 1057.5 & 3361.4 & \\
\hline a3 & 2725.3 & 1049.1 & 3396.5 & \\
\hline a4 & 2608.5 & 1024.5 & 3801.8 & \\
\hline a5 & 2784.5 & 1055.9 & 3321.7 & \multirow{2}{*}{ vobs $(\mathrm{N} 31-\mathrm{H})=1569$} \\
\hline a6 & 2748.6 & 1057.1 & 3338.1 & \\
\hline AAIL & 2739.5 & --- & --- & --- \\
\hline $\mathrm{CH}_{3} \mathrm{OH}$ & --- & 1018.7 & 3803.4 & 1026.0 \\
\hline
\end{tabular}

Table 5: Values of some major peaks in the theoretical and experimental IR spectra of [bmim] [Ala]+ $\mathrm{CH}_{3} \mathrm{OH}$.

\section{References}

1. Fukumoto K, Yoshizawa M, Ohno H (2005) Room temperature ionic liquids from 20 natural amino acids. J Am Chem Soc 127: 2398-2399.

2. Ohno H, Fukumoto K (2007) Amino acid ionic liquids. Acc Chem Res 40: 1122 1129.

3. Plaquevent JC, Levillain J, Guillen F, Malhiac C, Gaumont AC (2008) Ionic liquids: new targets and media for alpha-amino acid and peptide chemistry.
Chem Rev 108: 5035-5060.

4. Swatloski RP, Spear SK, Holbery JD (2002) Dissolution of cellulose with ionic liquids. J Am Chem Soc 124: 4974-4795.

5. Handy ST (2003) Greener solvents: room temperature ionic liquids from biorenewable sources. Chem Eur J 9: 2938-2944.

6. Rogers RD, Seddon KR (2003) lonic liquids-solvents of the future? Science 302: $792-793$

7. Rogers RD, Seddon KR (2002) lonic liquids: industrial applications for green chemistry. Proceedings of a Symposium held 1-5 April 2001 in San Diego, California.

8. Welton T (1999) Room-temperature ionic liquids: solvents for synthesis and catalysis. Chem Rev 99: 2071-2083.

9. Welton T (2004) lonic liquids in catalysis. Coord Chem Rev 248: 2459-2477.

10. Horvath IT (2008) Solvents from nature. Green Chem 10: 1024-1028.

11. Wassercheid $P$, Keim W (2000) lonic liquids-new "solutions" for transition metal catalysis. Angew Chem Int Ed 39: 3772-3789.

12. Plechkova NV, Seddon KR (2008) Applications of ionic liquids in the chemical industry. Chem Soc Rev 37: 123-150.

13. Zhang JM, Zhang SJ, Dong K (2006) Supported absorption of $\mathrm{CO}_{2}$ by tetrabutylphosphonium amino acid ionic liquids. Chem Eur J 12: 4021-4026.

14. Fukumoto K, Ohno H (2006) Design and synthesis of hydrophobic and chira anions from amino acids as precursor for functional ionic liquids. Chem Commun 3081-3083

15. Luo SP, Xu DQ Yue HD (2006) Synthesis and properties of novel chiral-aminefunctionalized ionic liquids. Tetrahedron: Asymmetry 17: 2028-2033.

16. Tao GH, He L, Sun N, Kou Y (2005) New generation ionic liquids: cations derived from amino acids. Chem Commun 28: 3562-3564.

17. Chen X, Li X, Hu A, Wang F (2008) Advances in chiral ionic liquids derived from natural amino acids. Tetrahedron: Asymmetry 19: 1-14.

18. Pretti C, Chiappe C, Pieraccini D, Gregori M, Abramo F, et al. (2006) Acute toxicity of ionic liquids to the zebrafish. Green Chem 8: 238-240.

19. Fang DW, Guan W, Tong J, Wang Z W, Yang J Z (2008) Study on physicochemical properties of ionic liquids based on alanine [Cnmim][Ala] $(n=2,3,4,5,6)$. J Phys Chem B 112: 7499-7505.

20. Yang JZ, Zhang QG, Wang B, Tong J (2006) Study on the properties of amino acid ionic liquid EMIGly. J Phys Chem B 110: 22521-22524.

21. Gomez E, Gonzalez B, Calvar N, Tojo E, Dominguez A (2006) Physical Properties of Pure 1-Ethyl-3-methylimidazolium Ethylsulfate and its Binary Mixtures With Ethanol and Water at Several Temperatures. J Chem Eng Data 51: 2096-2102. 
Citation: Yan S, Zhang H, Liu J, Wang H (2015) Study On The Structures And Interactions Binary System Composed By The lonic Liquids [Bmim] [Ala] and Water /Methanol Using The Vibrational Spectra. J Biomol Res Ther 4: 125. doi:10.4172/2167-7956.1000125

22. Gonzalez EJ, Gonzalez B, Calvar N, Dominguez A (2007) Physical Properties

23. Binary Mixtures of the Ionic Liquid 1-Ethyl-3-methylimidazolium Ethyl Sulfate with

24. Several Alcohols at $T=(298.15,313.15$, and 328.15) $\mathrm{K}$ and Atmospheric Pressure. J

25. Chem Eng Data 52: 1641-1648.

26. Parr RG, Yang W (1989) Density-functional theory of atoms and molecules. Oxford University Press.

27. Koch W, Holthausen M C (2000) A chemist's guide to density functional theory. Wiley-VCH, New York.

28. Fuqiang B, Kathryn NR, James WG (2002) Recent applications of density functional theory calculations to biomolecules. Theor Chem Acc 108: 1-11.

29. 26.Frisch MJ, Trucks GW, Schlegel HB, Scuseria GE, Robb MA, et al. (2003) Gaussian03. Gaussian Inc, Pittsburgh.

30. Reed AE, Curtiss LA, Weinhold F (1988) Intermolecular interactions from a natural bond orbital, donor-acceptor viewpoint. Chem Rev 88: 899-926.

31. Foster JP, Weinhold F (1980) Natural hybrid orbitals. J Am Chem Soc 102 7211-7218.

32. Dong K, Zhang S, Wang D, Yao X (2006) Hydrogen bonds in imidazolium ionic liquids. J Phys Chem A 110: 9775-9782.

33. Frisch MJ, Pople JA, Binkley JS (1984) Self-consistent molecular orbital methods Supplementary functions for Gaussian basis sets. J Chem Phys 80 : 3265-3269.

34. Clark T, Chandrasekhar J, Spitznagel GW (1983) Efficient diffuse functionaugmented basis sets for anion calculations. III: The $3-21+G$ basis set for firstrow elements, Li-F. J Comp Chem 4: 294-301.

35. Ditchfield R, Hehre WJ (1971) Self-Consistent Molecular-Orbital Methods. IX. An Extended Gaussian-Type Basis for Molecular-Orbital Studies of Organic Molecules. J Chem Phys 54: 72-77.
36. Biegler-Konig F, Bader RF (2002) AIM 2000, Version 2.

37. Bondi A (1964) Van der Waals volumes and radii. J Phys Chem 68: 441-451.

38. Boys SF, Bernardi F (1970) Calculations of small molecular interactions by differences of separate total energies Some procedures with reduced errors. Mol Phys 19: 553-566.

39. van DFB, van Duijineveldt-van de Rijdt JCM, van Lenthe JH (1994) State of the art in counterpoise theory. Chem Rev 94: 1873-1885.

40. Bader RFW (1990) Atom in Molecules: A Quantum Theory, International Series of Monographs in Chemistry. Oxford University Press, Oxford.

41. van Santen RA, Kramer GJ (1995) Reactivity theory of zeolitic broensted acidic sites. Chem Rev 95: 637-660.

42. Johnston KP, Meredith JC, Harrison KL (2006) Spectroscopy: the fourth vertex on the molecular thermodynamics tetrahedron. Fluid Phase Equilib 116: 385394.

43. Tran CD, Lacerda SHD, Oliveira D (2003) Absorption of Water by RoomTemperrature Ionic Liquids:Effect of Anions on Concentration and State of Water. Appl. Spectrosc 57: 152-157.

44. 41.Carmichael AJ, Seddon KR (2000) Polarity Study of Some 1-Alkyl-3methylimidazolium Ambient-Temperature lonic Liquids with the Solvatochromic dye, Nile Red. J Phys Org Chem 13: 591-595.

45. 42. Law G, Watson PR (2001) Surface Orientation in lonic Liquids. Chem Phys Lett 345: 1-4.

46. 43. Seddon KR, Stark A, Torres MJ (2000) Influence of Chloride, Water and Organic Solvents on the Physical Properties of Ionic Liquids. Pure Appl Chem 72: $2275-2287$.

47. 44. Yang Y, Zhang W, Pei S, Shao J, Huang W, et al. (2005) Blue-shifted and red-shifted hydrogen bonds: theoretical study of the $\mathrm{CH} 3 \mathrm{CHO} \cdot \cdots \mathrm{NH} 3$ complexes. J Mol Struct (Theochem) 732: 33-37.

48. 45. Rodriguez H, Brennecke JF (2006) Temperature and Composition Dependence of the Density and Viscosity of Binary Mixtures of Water + Ionic Liquid. J Chem Eng. Data 51: 2145-2155. 